\title{
KONFIGURASI INTER-VLAN PADA CISCO BERBASIS GRAPHICS USER INTERFACE (GUI) SEBAGAI PEMBELAJARAN PERALATAN JARINGAN KOMPUTER CISCO
}

\author{
Aditya Wisnu Pratama, Hero Wintolo, Yenni Astuti \\ Jurusan Teknik Informatika \\ Sekolah Tinggi Teknologi Adisutjipto Yogyakarta \\ informatika@stta.ac.id
}

\begin{abstract}
Computer network using LAN has limitations in terms of the large number of computers that will be connected to the switch equipment. This limitation can be overcome by connecting the LAN between each other using a router. Networks inter LAN still pose a problem in terms of safety, although the amount can be overcome. To overcome the problem requires a LAN in a small group that is often known as Virtual Local Area Network (VLAN). VLAN can be connected as is often done on the LAN in general with the addition of some equipment that is able to be used as the connecting or known by the name of inter-VLAN. inter-VLAN configuration can be done directly and indirectly. the configuration directly by configuring the network equipment such as switches and routers, while the indirect configuration can be done using packet tracer. In doing inter-VLAN configuration requires a command performed by an administrator. Commands that is configured on the network equipment is a command that is still a command line or a particular script. For people who have not worked as a network administrator needed a software Graphics User Interface (GUI) for ease in studying network administration. Software Graphics User Interface (GUI) can facilitate a person who has worked as an administrator to configure inter-VLAN.
\end{abstract}

Keyword: Virtual Local Area Network (VLAN), Inter-VLAN, Graphics User Interface (GUI)

\section{Latar Belakang}

Jaringan komputer menggunakan LAN mempunyai keterbatasan dalam hal banyaknya jumlah komputer yang akan dihubungkan ke peralatan switch. Keterbatasan ini dapat diatasi dengan menghubungkan antar LAN satu dengan lainnya menggunakan router. Jaringan antar LAN masih menimbulkan masalah dari segi keamanannya walaupun secara jumlah dapat diatasi. Untuk mengatasi masalah tersebut dibutuhkan LAN dalam kelompok kecil yang sering dikenal dengan nama Virtual Local Area Network (VLAN). VLAN dapat dihubungkan seperti halnya yang sering dilakukan pada LAN pada umumnya dengan penambahan beberapa peralatan yang mampu untuk digunakan sebagai penghubungnya atau dikenal dengan nama inter-VLAN. Konfigurasi inter-VLAN sendiri dapat dilakukan secara langsung dan tidak langsung. Konfigurasi secara langsung ini yaitu dengan melakukan konfigurasi ke peralatan jaringan seperti switch dan router, sedangkan konfigurasi secara tidak langsung bisa dilakukan dengan menggunakan packet tracer. Dalam melakukan konfigurasi inter-VLAN dibutuhkan suatu perintah atau command yang dilakukan oleh seorang administrator. Perintah atau command yang dikonfigurasikan pada peralatan jaringan merupakan suatu perintah yang masih berupa command line atau script tertentu. Bagi orang yang belum berprofesi sebagai 
administrator pada suatu jaringan dibutuhkan suatu perangkat lunak berbasis Graphics User Interface (GUI) untuk mempermudah dalam mempelajari administrasi jaringan.

\section{Landasan Teori}

\section{Administrasi Jaringan Cisco}

Cisco adalah peralatan utama yang banyak digunakan pada jaringan area luas atau WAN. Peralatan yang diproduksi oleh cisco berupa router dan switch serta peralatan jaringan computer lainnya. Dengan cisco router, informasi dapat diteruskan ke alamat-alamat yang berjauhan dan berada di jaringan komputer yang berlainan yang bertujuan untuk dapat meneruskan paket data dari suatu LAN ke LAN lainnya,

\section{Router}

Router adalah perangkat jaringan yang digunakan untuk membagi protokol kepada anggota jaringan yang lainnya, dengan adanya router maka sebuah protokol dapat di-sharing kepada perangkat jaringan lain. Ciri - ciri router adalah adanya fasilitas Dynamic Host Configuration Procotol (DHCP) yang dapat memberikan user keuntungan dalam membagi IP Address secara oromatis. Salah satu contoh Router dapat dilihat pada Gambar 1.

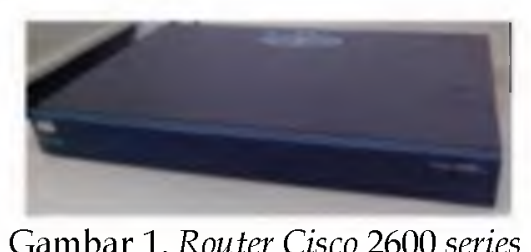

\section{Switch}

Switch adalah komponen jaringan yang digunakan untuk menghubungkan beberapa HUB untuk membentuk jaringan yang lebih besar atau menghubungkan komputer komputer yang mempunyai kebutuhan bandwidth yang besar. Switch memberikan unjuk kerja yang jauh lebih baik dari pada HUB dengan harga yang sama atau sedikit lebih mahal. Gambar switch dapat dilihat pada Gambar 2.

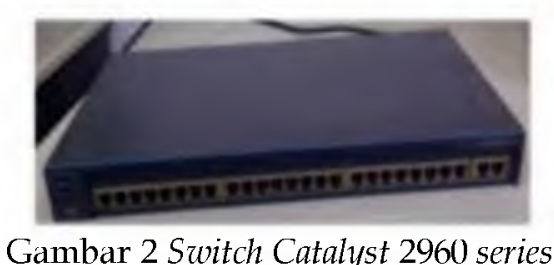

\section{Virtual Local Area Network (VLAN)}

VLAN merupakan suatu model jaringan yang tidak terbatas pada lokasi fisik seperti LAN, hal ini mengakibatkan suatu jaringan dapat dikonfigurasi secara virtual tanpa harus menuruti lokasi fisik peralatan. Penggunaan VLAN akan membuat pengaturan jaringan menjadi sangat fleksibel karena dapat dibuat segmen yang bergantung pada organisasi tanpa harus bergantung pada lokasi workstation. Contoh VLAN dapat dilihat pada gambar 3 


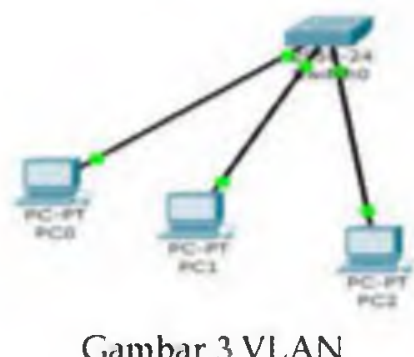

\section{Inter-VLAN}

Pada sebuah VLAN memiliki satu broadcast domain, sehingga pada satu buah komputer tidak dapat terkoneksi dengan komputer yang berbeda VLAN. Agar komputer yang berbeda VLAN dapat terkoneksi maka dibutuhkan perangkat layer-3 yaitu router. Persyaratan router yang dapat dipakai untuk routing VLAN adalah router tersebut harus bisa dibuat trunking ke switch. Oleh karena itu, pada router harus tersedia interface fastethernet dan Internetwork Operating System (IOS) untuk router tersebut juga harus mendukung trunking. Gambar salah satu contoh inter-VLAN dapat dilihat pada gambar 4.

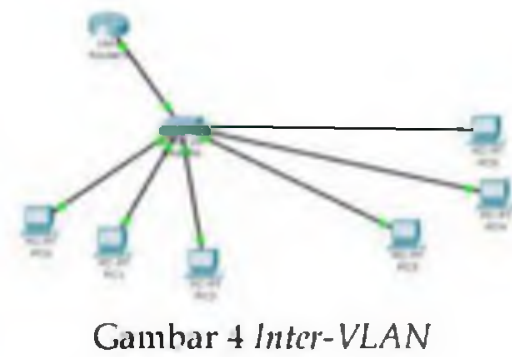

\section{Perancangan Sistem}

\section{Spesifikasi Hardware dan Software}

Dalam melakukan uji coba atau untuk menjalankan aplikasi dengan kinerja sistem yang maksimal, dibutuhkan suatu media sebagai pendukungnya yaitu hardware ( perangkat keras) software (perangkat lunak).

\section{Spesifikasi Hardware}

Hardware merupakan suatu komponen yang berfungsi untuk mendukung sistem komputer. Hardware berperan dalam input data, proses, dan menampilkan output. Berikut ini adalah spesifikasi hardware yang digunakan dalam membuat aplikasi ini :

1. Processor Intel Core i3 CPU 2,53 GHz.

2. RAM 1 GB,

3. Harddisk $250 \mathrm{~GB}$,

4. Keyboard dan mouse standar.

5. Router Cisco 2600 series.

6. Switch Catalyst 2950 series.

7. Kabel UTP dan kabel console.

8. Spesifikasi Software

Adapun spesifikasi softwore atau perangkat lunak yang digunakan dalam pembuatan aplikasi ini adalah :

1. Sistem Operasi Windows 7 


\section{Borland Delphi 7.0}

\section{Perencanaan Kebutuhan}

Dalam perencanaan kebutuhan terdapat dua tahapan, yaitu : analisa sistem, analisa kebutuhan pengguna.

\section{Kebutuhan Sistem}

Jaringan komputer menjadi salah satu solusi dalam melakukan sharing atau komunikasi antar komputer karena dapat memudahkan antara pengguna komputer satu dan lainnya dengan menggunakan media penghubung kabel dan non-kabel. Jaringan komputer menggunakan Local Area Network (LAN) memiliki keterbatasan banyaknya jumlah komputer dan jarak yang dapat diatasi dengan membuat suatu jaringan komputer dengan membuat jaringan menggunakan peralatan jaringan cisco seperti router dan switch. Akan tetapi masih memiliki keterbatasan dari segi keamanan maka dibuatlah LAN dalam kelompok kecil yang biasa dikenal dengan nama Virtual Local Area Network (VLAN). Agar VLAN dapat mencakup banyak komputer dan dapat dilakukan pada sebuah jaringan yang besar dilakukan suatu konfigurasi VLAN tingkat lanjut dengan menghubungkan antar VLAN dan biasa dikenal dengan nama inter-VLAN. Seseorang yang belum berprofesi sebagai administrator akan dimudahkan dalam melakukan konfigurasi inter-VLAN dengan memberikan fasilitas berupa perangkat lunak berbasis Graphics User Interface (GUI).

\section{Kebutuhan Pengguna}

Bagi seorang administrator, melakukan konfigurasi jaringan merupakan hal yang sangat penting dan menjadi kebutuhan utama. Seorang administrator wajib mengetahui perintah perintah dalam melakukan konfigurasi berbagai macam administrasi jaringan seperti pembuatan inter-VLAN. Namun bagi seseorang ingin menjadi seorang administrator berbagai macam perintah tersebut akan sulit untuk dimengerti dan akan mengalami kesulitan dalam pembuatan jaringan dalam kelompok besar seperti inter-VLAN. Untuk itu dibutuhkan suatu perangkat lunak berbasis GUI yang di dalamnya terdapat perintah - perintah dari konfigurasi inter-VLAN. Perangkat lunak tersebut nantinya akan memberikan kemudahan bagi seseorang yang ingin menjadi administrator dalam memperlajari lebih dalam mengenai administrasi jaringan dengan menggunakan peralatan jaringan cisco.

\section{System Flowchart}

Rancangan ini digunakan untuk mendesain dan merepresentasikan suatu program sebelum memulai pembuatan yang berfungsi untuk mempermudah dalam menentukan alur logika program yang akan dibuat dan seesudah pembuatan program dengan fungsi untuk menjelaskan alur program kepada orang lain atau pengguna. Pada rancangan flowchart aplikasi konfigurasi inter-VLAN pada cisco berbasis GUI terdiri dari 2 bagian, yaitu proses konfigurasi VLAN di switch dan proses konfigurasi VLAN di router. Rancangan ini dapat dilihat pada gambar 5 . 


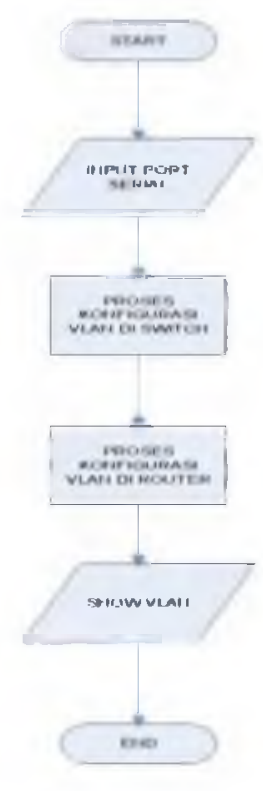

Gambar 5 Perancangan Flowchart konfigurasi inter-VLAN pada cisco berbasis Graphics User Interface (GUI)

\section{Perancangan Antarmuka}

Secara umum perancangan antarmuka adalah berbentuk sebuah jendela - jendela yang digunakan sebagai penghubung antara pengguna (brainware) dengan komputer dan digunakan untuk melakukan interaksi antara pemakai dan aplikasi sehingga perancangan antarmuka lebih user friendly atau mudah dimengerti oleh pengguna. Dalam perangkat lunak ini terdapat dua buah cara konfigurasi, yaitu konfigurasi VLAN di switch dan konfigurasi VLAN di router.

\section{Implementasi dan Analisa}

\section{Penjelasan Aplikasi}

Penjelasan Aplikasi merupakan tahapan dimana aplikasi “Konfigurasi inter-VLAN pada Cisco berbasis Graphics User Interface (GUI) sebagai Pembelajaran Peralatan Jaringan Cisco" akan di-install di komputer yang digunakan untuk melakukan konfigurasi. Aplikasi yang sudah terinstal digunakan untuk melakukan konfigurasi inter-VLAN. Tahap pertama yaitu mengaktifkan port yang akan digunakan dalam melakukan konfigurasi yang dilakukan pada switch dan roouter dengan menggunakan kabel console sebagai media penghubungnya. Penjelasan aplikasi terdiri dari form utama, konfigurasi VLAN di switch dan konfigurasi VLAN di router,

\section{Uji Fungsi}

Sesuai rancangan pada gambar 5, didapat hasil penerapan aplikasi konfigurasi interVLAN dengan tahapan - tahapan sebagai berikut :

1. Setelah aplikasi dijalankan maka akan muncul menu utama yang berisi beberapa tombol untuk membuka form yang nantinya digunakan untuk melakukan konfigurasi.

2. Langkah selanjutnya adalah menghubungkan kabel serial console dari komputer ke port console yang ada di switch dan melakukan konfigurasi inter-VLAN di switch dengan memilih tombol konfigurasi VLAN di switch yang ada pada menu utama. 
3. Setelah masuk ke form konfigurasi VLAN di switch langkah berikutnya adalah memilih port yang akan dipakai sebagai jalur akses dari perangkat lunak ke peralatan jaringan cisco switch kemudian pilih connect untuk menghubungkannya.

4. Setelah memilih port kemudian masuk ke form pengaturan VLAN dan memulai melakukan konfigurasi dengan mengisi ID VLAN dan nama VLAN pada kolom yang sudah disediakan.

5. Kemudian untuk menentukan mode access yang akan menentukan akses VLAN atau akses ke router. Untuk akses yang akan dipakai VLAN mode yang dipilih adalah mode access, sedangkan untuk akses yang akan dipakai router mode yang dipilih adalah mode trunk.

6. Konfigurasi VLAN di switch sudah dilakukan, kabel serial console dipindahkan ke port console yang ada di router dan kemudian memilih tombol konfigurasi VLAN di router yang ada pada menu utama.

7. Setelah masuk ke form konfigurasi VLAN di router, tahap berikutnya menentukan port yang akan dipakai kabel console dengan memilih tombol configure kemudian pilih connect untuk menghubungkan.

8. Setelah terhubung maka masuk ke form pengaturan inter-VLAN yang berisi kolom untuk mengatur jalur akses router ke switch dan pemberian default gatewoay yang akan dipakai oleh masing - masing VLAN.

Setelah konfigurasi dilakukan dilakukan pengecekan dengan menggunakan mekanisme ping dari komputer satu ke default komputer lain dan juga ke alamat IP komputer tersebut. Apabila hasil dari ping tersebut reply maka, konfigurasi inter-VLAN sudah berhasil diterapkan di jaringan komputer. Hasil dari pengujian tersebut dapat dilihat pada gambar 6 dan gambar 7.

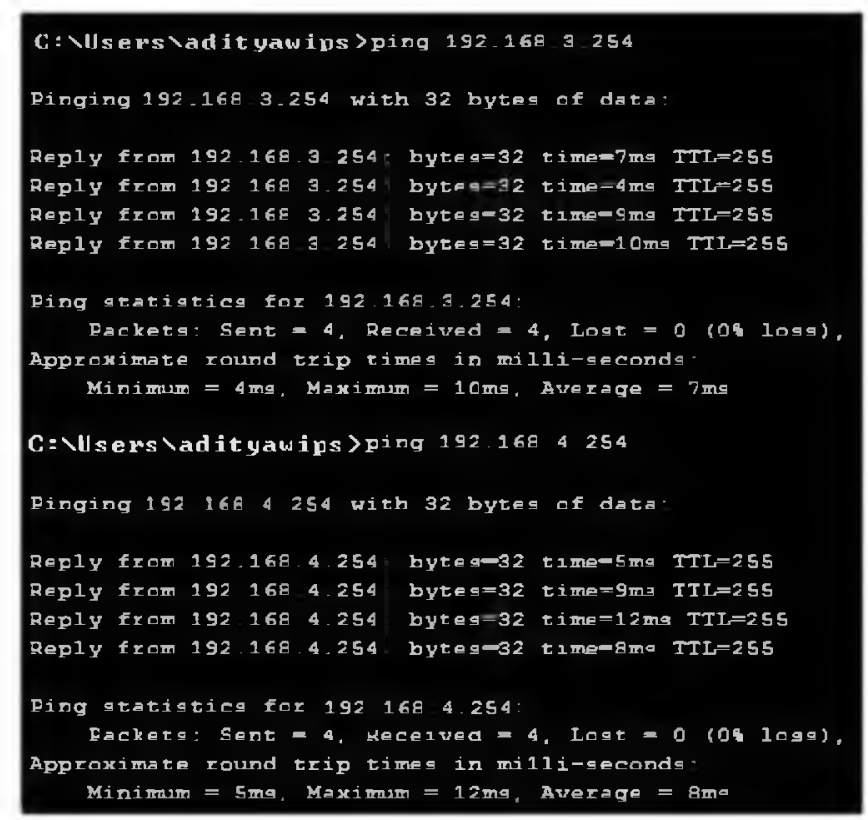

Gambar 6 Ping ke Default gateway

Hasil pengujian dilakukan dengan melakukan ping ke default gateway masing-masing VLAN yang telah dibuat ketika melakukan konfigurasi di router. 


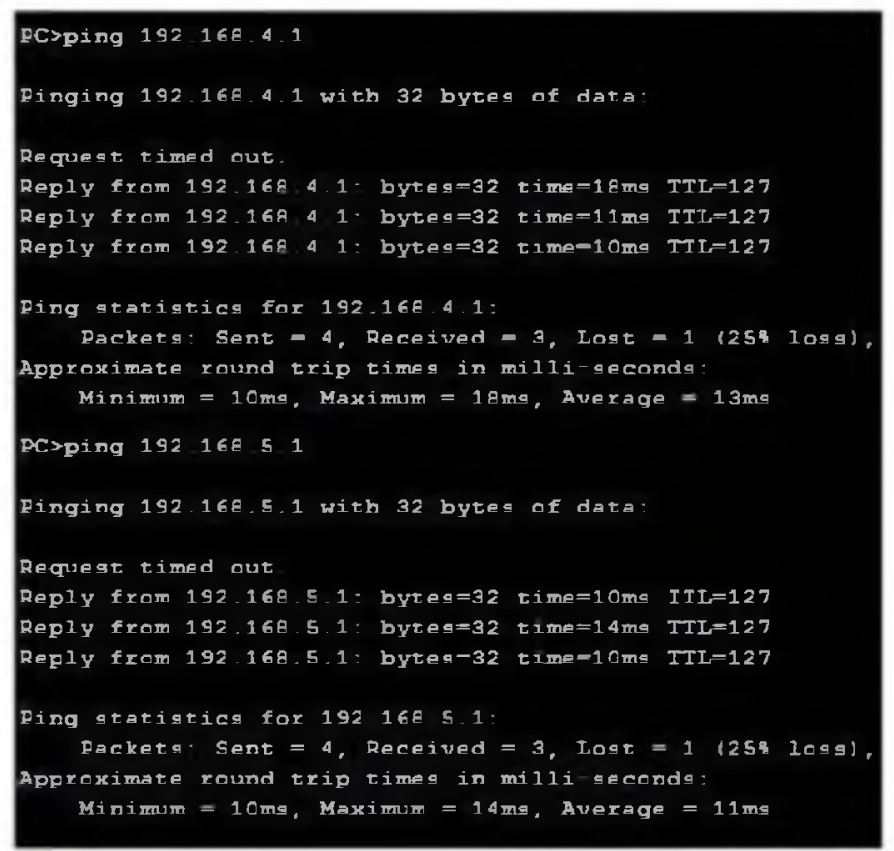

Gambar 7 Ping ke Alamat IP Komputer lain

Sebelum melakukan ping ke komputet lainnya dilakukan pengisian alamat IP terlebih dahulu pada masing - masing komputer agar dapat diterjemahkan oleh peralatan jaringan cisco yaitu switch dan router.

\section{Kesimpulan}

Dari hasil uji coba yang dilakukan dapat ditarik beberapa kesimpulan, antara lain :

1. Perangkat lunak yang dihasilkan memiliki tampilan grafis dengan cara kerja menggunakan click mouse dapat membantu seseorang yang belum berprofesi sebagai administrator jaringan komputer dalam membuat VLAN.

2. VLAN yang dibuat menggunakan perangkat lunak dapat saling dihubungkan menjadi sebuah inter-VLAN dan dikirimkan ke peralatan jaringan komputer switch dan router cisco menggunakan kabel console.

3. Berdasarkan hasil survey hasil rancangan perangkat lunak dalam tugas akhir ini mendapat respon yang baik dibandingkan dengan menggunakan aplikasi Teraterm dan simulasi pada Packet Tracer.

\section{Daftar Pustaka}

C. Setiawan, Yudha. 2005. Tip Delphie. Andi Offset(Andi). Yogyakarta.

Sofana, Iwan. Cisco CCNA dan Jaringan Komputer. Informatika Bandung. Bandung

Syafrizal, 2005, Pengantar Jaringan Komputer, Andi Offset (Andi), Yogyakarta.

Sutanta, 2005, Komunikasi Data dan Jaringan Komputer, Graha Ilmu, Yogyakarta.

Sotedjo, dkk, 2006, Konsep dan Aplikasi Pemrograman Client Server dan Sistem Terdisrtibusi, Andi

Offset (Andi), Yogyakarta.

http:/komunitasituny.blogspot.com/2012/03/inter-vlan-routing-cisco-paket-tracert.html

(diakses pada tanggal 30 Januari 2013) 
Aditya Wisnu Pratama, Hero Wintolo, Yenni Astuti

https://nonda.wordpress.com/2012/04/09/bagaimana-konfigurasi-inter-vlan-routing-pada-layer-3switchi (diakses pada tanggal 13 Mei 2013) 